Article

\title{
Synergistic Promotion on Tyrosinase Inhibition by Antioxidants
}

\author{
Yan Wang ${ }^{1,+}{ }^{\mathbb{D}}$, Mi-Mi Hao ${ }^{1,+}$, Ying Sun ${ }^{1}$, Li-Feng Wang ${ }^{1}$, Hao Wang ${ }^{1}$, Yan-Jun Zhang ${ }^{1}$, \\ Hong-Yan $\mathrm{Li}^{2}$, Peng-Wei Zhuang ${ }^{1, *}$ and Zhen Yang ${ }^{1, *}$ \\ 1 Chinese Material Medical College, Tianjin State Key Laboratory of Modern Chinese Medicine, \\ Tianjin University of Traditional Chinese Medicine, Tianjin 300193, China; \\ wangyan@tjutcm.edu.cn (Y.W.); haomimi126@126.com (M.-M.H.); 13920257809@163.com (Y.S.); \\ wanglif930@163.com (L.-F.W.); 13920000655@139.com (H.W.); zyjsunye@163.com (Y.-J.Z.) \\ 2 Tianjin JiaShiTang Technology Co., Ltd., Tianjin 300457, China; lihongyan07@126.com \\ * Correspondence: zhuangpengwei@tjutcm.edu.cn (P.-W.Z.); yzwygb@126.com (Z.Y.); \\ Tel.: +86-225-9596225 (P.-W.Z.); +86-225-9596225 (Z.Y.) \\ + These two authors contributed equally to this work.
}

Received: 12 November 2017; Accepted: 2 January 2018; Published: 4 January 2018

\begin{abstract}
When exposed to ultraviolet radiation, the human skin produces profuse reactive oxygen species (ROS), which in turn activate a variety of biological responses. Mounting ROS levels activate tyrosinase by mobilizing $\alpha$-melanocyte-stimulating hormone in the epidermis and finally stimulates the melanocytes to produce melanin. Meanwhile, the Keap1-Nrf2/ARE pathway, which removes ROS, is activated at increased ROS levels, and antioxidant compounds facilitates the dissociation of Nrf2. In this study, we explored the possible suppressing effects of antioxidant compounds and tyrosine inhibitors on melanin formation and the promotory effects of these compounds on ROS scavenging. The antioxidant activity of glabridin (GLA), resveratrol (RES), oxyresveratrol (OXYR), and phenylethylresorcinol (PR) were investigated via the stable free radical 2,2-diphenyl-1-picrylhydrazyl method. The inhibitory effects of the four compounds and their mixtures on tyrosinase were evaluated. L-Tyrosine or 3-(3,4-dihydroxyphenyl)-L-alanine (L-DOPA) was used as a substrate. The results showed that all mixtures did not exhibit synergistic effects with the L-tyrosine as a substrate, suggesting that L-tyrosine is not suitable as a substrate. However, the mixtures of "GLA:RES," "GLA:OXYR," "OXYR:RES," and "PR:RES" demonstrated synergistic effects $(\mathrm{CI}<0.9, p<0.05)$, whereas "GLA:RES" and "PR:OXYR" indicated an additive effect (0.9 ditive1, $p<0.05$ ). Furthermore, we used a molecular docking strategy to study the interactions of the four compounds with tyrosinase and L-DOPA. The molecular docking result is consistent with that of the experiment. Finally, we selected RES + OXYR and used PIG1 cells to verify whether OXYR synergistically promotes RES activity on tyrosinase. The two agents had a synergistic inhibitory effect on tyrosinase activity. These results provided a novel synergistic strategy for antioxidants and tyrosinase inhibitors, and this strategy is useful in skin injury treatment.
\end{abstract}

Keywords: tyrosinase inhibitory activity; antioxidant activity; synergistic effect; molecular docking strategy

\section{Introduction}

The human skin is constantly exposed to ultraviolet radiation (UVR), which is an induction factor of reactive oxygen species (ROS). Excessive ROS levels can lead to the formation of pathological skin pigmentation or even direct DNA damage and induce skin injury. Antioxidant defense systems help ameliorate oxidative stress [1-3]. Nuclear factor E2-related factor 2 (Nrf2) is a transcription factor that 
may play a key role in UVR-mediated oxidative stress. Nrf2 regulates several phase II detoxification and antioxidant genes involved in cellular defenses against oxidative stress $[4,5]$.

Skin pigmentation is another mechanism for the prevention of damage due to UVR. Melanin absorbs UVR, thereby protecting skin cells from UVR damage [6]. Therefore, normal skin pigmentation is essential for human health [7]. Tyrosinase (EC 1.14.18.1) is a copper-containing enzyme, widely distributed in fungi, plants, and animals [8]. It catalyzes the pigmentation of skin and is directly related with pigmentation disorders in mammals $[9,10]$. It is a key target for the discovery and screening of novel inhibitors because of its central role in melanogenesis.

An extremely interesting and delicate relationship exists between antioxidant defense systems and melanogenesis. This relationship is associated with ROS scavenging. The synergistic effect in this relationship increases the effectiveness of antioxidants in scavenging free radicals while tyrosinase inhibitors work, thus reducing melanin production.

Glabridin (GLA) is an isoflavone isolated from the root of Glycyrrhiza glabra Linn. It has various pharmacological activities and is capable of inhibiting tyrosinase [11,12]. Resveratrol (RES) is a kind of polyphenolic phytoalexin that is derived from plants. It exhibits broad health benefits, such as antioxidative, anti-inflammatory, and anti-proliferative activities and tyrosinase inhibition [13]. Oxyresveratrol (OXYR) is a powerful inhibitor of tyrosinase and can be used as a skin-whitening and anti-browning agent [14]. Phenylethylresorcinol (PR) is a new skin-whitening agent with strong bioactive ability to inhibit tyrosinase activity [15].

To study inhibitors related to tyrosinase, we evaluated the antioxidant activity and tyrosinase inhibitory activity of four compounds. We found that if these four compounds are in accordance with certain rules, then they can play a synergistic role when combined. This paper is the first written report on this synergistic effect. We also performed molecular docking to study the interactions of each of these compounds with tyrosinase and kelch-like ECH-associated protein 1 (keap1).

\section{Materials and Methods}

\subsection{Materials and Instruments}

GLA $(\geq 95 \%)$, RES $(\geq 98 \%)$, OXYR $(\geq 98 \%)$, and PR $(\geq 98 \%)$ are acquired from SABINSA (Sabinsa Corporation, Piscataway, NJ, USA). Free radical 2,2-diphenyl-1-picrylhydrazyl (DPPH) and $25 \mathrm{KU}$ solid tyrosinase from mushroom are all obtained from TCI (Shanghai, China) and Worthington Biochemical (Worthington Biochemical Corporation, Monroe, MI, USA), respectively. Dimethyl sulfoxide (DMSO), 3-(3,4-dihydroxyphenyl)-L-alanine (L-DOPA), and tyrosine are purchased from Sigma Chemical Company (Sigma Aldrich, Munich, Germany). All other chemicals purchased are of high purity and reagent grade.

\subsection{Preparation of Antioxidant Solutions}

GLA, RES, OXYR, and PR were dissolved and diluted in ethanol.

\subsection{DPPH Free Radical-Scavenging Capacity Assay}

The DPPH free radical-scavenging capacity of the samples are determined according to the method of a previous study [16] with slight modifications. Samples (1001) of various concentrations are added to $100 \mu \mathrm{L}$ of $0.1 \mathrm{mmol} / \mathrm{L}$ DPPH solution in methanol at room temperature. After $30 \mathrm{~min}$, the absorbance is measured at $517 \mathrm{~nm}$ with a UV-visible spectrophotometer (MAPADA UV-6100PCS, Shanghai, China). The percentage of free radical (DPPH) scavenging activity (I\%) is calculated according to following formula:

$$
I \%=\frac{O D_{c k}-O D_{\text {sample }}}{O D_{c k}} \times 100
$$


where $O D_{c k}$ is the absorbance of the control reaction, which involves all the reagents except the test compound, and $O D_{\text {sample }}$ is the absorbance of the test compound.

\subsection{Preparation of Individual Solutions and Mixtures}

The GLA, RES, OXYR, and PR are dissolved in a mixture of sodium phosphate buffer (PBS, $\mathrm{pH}=6.8)$ and DMSO (80:20), and the prepared solutions are diluted with PBS. Two different individual solutions of GLA, RES, OXYR, and PR are prepared at a ratio of 1:1 [17].

\subsection{Mushroom Tyrosinase Inhibitory Assay}

Inhibitory activity against tyrosinase is examined through an improved spectrophotometric method using L-DOPA and L-tyrosine as substrates. When L-tyrosine is used as the substrate, the reaction mixture is combined with $80 \mu \mathrm{L}$ of $0.1 \mathrm{mM}$ PBS, $40 \mu \mathrm{L}$ of $5 \mathrm{mM}$ L-tyrosine [17], and $40 \mu \mathrm{L}$ of GLA, OXYR, PR, RES, GLA + OXYR, GLA + PR, RES + GLA, RES + OXYR, RES + PR, or OXYR + PR. The reaction mixture is incubated at $37^{\circ} \mathrm{C}$ for $15 \mathrm{~min}$. Mushroom tyrosinase $(40 \mu \mathrm{L}, 200$ units $/ \mathrm{mL})$ is added to the reaction mixture and incubated at $30^{\circ} \mathrm{C}$ for $20 \mathrm{~min}$.

When L-DOPA is used as the substrate, (1) the reaction mixture is mixed with $80 \mu \mathrm{L}$ of $0.1 \mathrm{mM}$ PBS, $40 \mu \mathrm{L}$ of $5 \mathrm{mM}$ L-DOPA, and $40 \mu \mathrm{L}$ of GLA, OXYR, PR, GLA + OXYR, GLA + PR of OXYR + PR at different concentrations. The reaction mixture is incubated at $37^{\circ} \mathrm{C}$ for $15 \mathrm{~min}$. Subsequently, $40 \mu \mathrm{L}$ of 100 units $/ \mathrm{mL}$ mushroom tyrosinase is added to the reaction mixtures and incubated at $37^{\circ} \mathrm{C}$ for $20 \mathrm{~min}$. (2) The other reaction mixture is mixed with $80 \mu \mathrm{L}$ of $0.1 \mathrm{mM}$ PBS, $40 \mu \mathrm{L}$ of mushroom tyrosinase (100 units $/ \mathrm{mL}$ ), and $40 \mu \mathrm{L}$ of RES, RES + GLA, RES + OXYR, or RES + PR at different concentrations. The reaction mixture is incubated at $37^{\circ} \mathrm{C}$ for $15 \mathrm{~min}$. Subsequently, $40 \mu \mathrm{L}$ of $5 \mathrm{mM} \mathrm{L}$-DOPA is added to the reaction mixture and incubated at $30^{\circ} \mathrm{C}$ for $20 \mathrm{~min}$.

Dopachrome formation is monitored at $475 \mathrm{~nm}$ with a UV-visible spectrophotometer (MAPADA UV-6100PCS). The rate of the inhibition of tyrosinase activity $(I \%)$ is determined according to the following formula:

$$
I \%=\frac{\left(A_{2}-A_{1}\right)-\left(B_{2}-B_{1}\right)}{\left(A_{2}-A_{1}\right)} \times 100
$$

where $A_{1}$ and $A_{2}$ are the absorbance values of the blank at $475 \mathrm{~nm}$ at $0 \mathrm{~min}$ and $20 \mathrm{~min}$, respectively, and $B_{1}$ and $B_{2}$ is the absorbance levels of the test sample at $475 \mathrm{~nm}$ at $0 \mathrm{~min}$ and $20 \mathrm{~min}$, respectively.

\subsection{Molecular Docking Strategy}

All calculations are performed in Discovery Studio 4.5 client, and the molecular docking studies are computed by CDOCKER module applied in Discovery Studio (Accelrys, San Diego, CA, USA). The structures of GLA, RES, OXYR, and PR are drawn and applied with CHARMm force field and then minimized to the closest local minimum. The crystal structures of tyrosinase (PDB ID: 2Y9X) and keap1 (PDB ID: 4IQK) of Agaricus bisporus are downloaded from the Protein Data Bank (http://www.rcsb.org/pdb/home/home.do). Before the docking study, the proteins are prepared by the "prepare protein" module in Discovery Studio 4.5. The ligands are extracted and crystallographic water molecules in the structures are deleted. The configuration and tautomeric states are corrected, and CHARMm force field is applied for minimization.

We calculated the root mean-square deviation (RMSD) between the docked conformation and crystal conformation to estimate the accuracy of CDOCKER. The binding ligands of 2Y9X and 4IQK are contracted and re-docked with receptors. When the molecular docking is completed, the best pose is selected on the basis of binding energy and interactions with active site residues. The best docked pose and co-crystallized conformation are then simply aligned, and the RMSD is calculated. A low value indicates accurate docking method [18]. 
Subsequently, the drawn compounds are docked to the receptors via the abovementioned method. In this study, three factors, namely, CDOCKER interaction energy, interactions between the compounds and receptor, and compound structures, comprehensively reverse the best pose.

\subsection{Drug Synergism Analysis of RSE and OXYR in PIG1 Cell}

To verify whether the above drugs have a synergistic inhibitory effect on tyrosinase activity in melanocytes, we selected RSE and OXYR for tyrosinase inhibition experiment in PIG1 cells.

\subsubsection{Cell Culture}

Immortalized human epidermal melanocyte cells from cell line PIG1 are obtained from Shanghai Guandao Bio-engineering Ltd. Co. (Shanghai, China). PIG1 cells are cultured at $37^{\circ} \mathrm{C}$ with $5 \% \mathrm{CO}_{2}$ in Medium 254 (\#M-254-500, Thermo Fisher Scientific, New York, NY, USA) supplemented with human melanocyte growth supplement-2 (Thermo Fisher Scientific, New York, NY, USA) and 5\% $(v / v)$ fetal bovine serum (Thermo Fisher Scientific, New York, NY, USA).

\subsubsection{UVB Irradiation Treatment}

The UVB source employed in this study is a Sigma SH4B light therapy device (Shanghai SIGMA High-tech Co., Ltd., Shanghai, China). The energy exposed is measured with a UV304B radiometer equipped with a UV304B sensor (Shenzhen XRC Electronics Co., Ltd., Shenzhen, China). UVB irradiation treatment is conducted when cells reached approximately $70 \%$ confluence according to the methods of Zeng et al. [19]. Before UVB irradiation, the supernatant is removed and replaced with PBS. The cells are vertically irradiated with $\mathrm{UVB}$, and the supernatant is immediately replaced with complete medium and RES, OXYR, or RES + OXYR and then incubated at $37^{\circ} \mathrm{C}$ with $5 \% \mathrm{CO}_{2}$. The control group receives the same treatment as the UVB group but is not administered any drug.

2.7.3. Detection of Cell Proliferation Activity by 3-(4,5-Dimethylthiazol-2-yl)-2,5-diphenyl-tetrazolium Bromide (MTT) Assay

Cell proliferation is detected according to the method of Verma et al. [20]. Cells are plated in 96-well plates at a density of $1 \times 10^{4}$ cells/well in $100 \mu \mathrm{L}$ of complete medium and then incubated at $37{ }^{\circ} \mathrm{C}$ with $5 \% \mathrm{CO}_{2}$ for $24 \mathrm{~h}$. The culture medium is removed and replaced with PBS. The cells are exposed to UVB irradiation at a dose of $300 \mathrm{~mJ} / \mathrm{cm}^{2}$. The medium is then immediately replaced with complete medium and RES or OXYR, and the cells are incubated for $24 \mathrm{~h}$. Cells are washed twice with PBS and added to a new culture medium without drugs. Subsequently, $10 \mu \mathrm{L}$ of $5 \mathrm{mg} \cdot \mathrm{mL}^{-1} \mathrm{MTT}$ (Gen-view, Calimesa, CA, USA) is added to the culture medium and incubated for $4 \mathrm{~h}$. The supernatant is removed and $100 \mu \mathrm{L}$ of DMSO (Aladdin, Shanghai, China) is added. Finally, absorbance was measured with an enzyme mark instrument at $490 \mathrm{~nm}$.

\subsubsection{Tyrosinase Activity Assay}

Tyrosinase activity is detected by western blotting. PIG1 cells $\left(1 \times 10^{4}\right.$ cells / well $)$ are seeded in 96-well plates and incubated for $24 \mathrm{~h}$ in $\mathrm{CO}_{2}$ until 70-80\% confluence is reached. Subsequently, the complete medium is replaced with $100 \mu \mathrm{L}$ of PBS, and the cells are exposed to $300 \mathrm{~mJ} / \mathrm{cm}^{2} \mathrm{UVB}$ irradiation. The medium is immediately replaced with complete medium and RES, OXYR, or RES + OXYR and incubated at $37^{\circ} \mathrm{C}$ with $5 \% \mathrm{CO}_{2}$ for $24 \mathrm{~h}$. The intracellular tyrosinase activity of the PIG1 cells are estimated by measuring the L-DOPA oxidation capacity according to the method of Rong et al. [21]. The PIG1 cells are washed twice with PBS, added to $50 \mu \mathrm{L}$ of $1 \%$ Triton X-100, and then incubated at $-80{ }^{\circ} \mathrm{C}$ for $30 \mathrm{~min}$, allowed to thaw at room temperature, added to $10 \mu \mathrm{L}$ of freshly prepared L-DOPA $\left(0.25 \%\right.$, Solarbio, Beijing, China), and incubated at $37^{\circ} \mathrm{C}$ for $120 \mathrm{~min}$. The products of the reaction are measured by reading the absorbance at $475 \mathrm{~nm}$. 


\subsection{Statistical Analysis}

The $50 \%$ inhibition concentration $\left(\mathrm{IC}_{50}\right.$ ) value is determined with SPSS 17.0 statistical software (International Business Machines Corporatio, Armonk, NY, USA). All experiments are performed at least in triplicate. Data are analyzed by unpaired Student's $t$-test, followed by Dunnett's multiple comparison test (SPSS version 17.0). P values lower than 0.05 are considered significant. The interactions are calculated using combination index (CI) according to [22]:

$$
C I=\frac{I C_{50 a m i x}}{I C_{50 a}}+\frac{I C_{50 b m i x}}{I C_{50 b}}
$$

where $I C_{50 a}$ and $I C_{50 b}$ are obtained from pure compounds, and $I C_{50 a m i x}$ is the concentration of individual compound in the mixture that cause $50 \%$ inhibition. Obtained CI values equal, smaller, or greater than 1 indicate an additive, synergistic, or antagonistic effect, respectively [23].

\section{Results and Discussion}

\subsection{The $I C_{50}$ Values of Antioxidant Solutions}

$\mathrm{IC}_{50}$ value is the concentration wherein $50 \%$ of activity of a compound is lost. The $\mathrm{IC}_{50}$ values of GLA, OXYR, PR, and RES solutions are shown in Table 1. GLA, OXYR, PR, and RES are efficient antioxidants, especially OXYR and PR, which demonstrated high free DPPH-scavenging activity. The results are similar to those of a previous report [24]. Meanwhile, GLA exhibited high antioxidant activity. Our results indicated that the capability of the compounds for free radical scavenging are ranked as follows: OXYR > PR > RES > GLA.

Table 1. The $\mathrm{IC}_{50}$ values of antioxidant solutions.

\begin{tabular}{cc}
\hline Samples & IC $_{\mathbf{5 0}}(\boldsymbol{\mu \mathbf { m o l } / \mathrm { L } )}$ \\
\hline OXYR & $76 \pm 0.07$ \\
PR & $119 \pm 0.07$ \\
RES & $142 \pm 0.03$ \\
GLA & $458 \pm 0.037$ \\
\hline
\end{tabular}

\subsection{The $I C_{50}$ Values of Individual Solutions of Tyrosinase Inhibitory Activities}

The $\mathrm{IC}_{50}$ values of GLA, OXYR, PR, and RES are shown in Table 2. Our results are consistent with the previous studies on GLA [1] and OXYR [25], which exhibited noncompetitive inhibition of tyrosinase activity with L-DOPA as substrate. RES did not inhibit tyrosinase activity in the L-DOPA substrate but was oxidized before L-tyrosine oxidation. Notably, RES is a Kcat or suicide-type inhibitor for tyrosinase [26]. The inhibitory activities of the samples with L-tyrosine and L-DOPA as substrates were ranked as follows: PR $>$ GLA $>$ OXYR $>$ RES and RES $>$ GLA $>$ OXYR $>$ PR, respectively.

Table 2. Inhibitory effects of single compounds on tyrosinase activity with L-tyrosine or L-DOPA as a substrate.

\begin{tabular}{ccc}
\hline \multirow{2}{*}{ Substance } & \multicolumn{2}{c}{ IC $_{\mathbf{5 0}}(\mu \mathrm{mol} / \mathrm{L})$} \\
\cline { 2 - 3 } & L-Tyrosine & L-DOPA \\
\hline GLA & $1.5 \pm 0.03$ & $6.0 \pm 0.23$ \\
OXYR & $2.5 \pm 0.06$ & $19.5 \pm 0.07$ \\
PR & $0.28 \pm 0.03$ & $35.5 \pm 0.06$ \\
RES & $23.0 \pm 0.05$ & $2.5 \pm 0.28$ \\
\hline
\end{tabular}




\subsection{Tyrosinase Inhibition and Synergistic Effects of Antioxidant and Tyrosinase Inhibitor}

The obtained $\mathrm{IC}_{50}$ and $\mathrm{CI}$ values of mixtures with L-tyrosine as substrate are summarized in Table 3. All of the mixtures showed an antagonistic effect $(\mathrm{CI}>1.1)$. The obtained $\mathrm{IC}_{50}$ and $\mathrm{CI}$ values of mixtures with the L-DOPA substrate are shown in Table 4. The CI values showed that the mixtures of "GLA:RES," “GLA:OXYR," “OXYR:RES," and "PR:RES” demonstrated synergistic effects. That is, the $\mathrm{CI}$ values were not greater than 1 , and the difference between $\mathrm{IC}_{50 \mathrm{mix}}$ and $\mathrm{IC}_{50 \text { add }}$ were significant). The mixtures of "GLA:RES" and "PR:OXYR" exhibited additive effect $(0.9 \leq \mathrm{CI} \leq 1.1)$.

Table 3. $\mathrm{IC}_{50}$ values and $\mathrm{CI}$ values of mixtures with L-tyrosine as a substrate.

\begin{tabular}{cccccc}
\hline Compounds & $\begin{array}{c}\text { Antioxidant } \\
\text { Activity }\end{array}$ & $\begin{array}{c}\text { Tyrosinase } \\
\text { Inhibitory Activity }\end{array}$ & $\begin{array}{c}\mathbf{I C}_{\text {50mix }} \\
(\mu \mathbf{m o l} / \mathbf{L})\end{array}$ & $\begin{array}{c}\text { IC }_{\text {50add }} \\
(\mu \mathbf{m o l} / \mathbf{L})\end{array}$ & CI \\
\hline PR:GLA & PR $>$ GLA & PR $<$ GLA & $16.5 \pm 0.04$ & $1.08 \pm 0.02 *$ & $2.03 \pm 0.02$ \\
GLA:RES & GLA < RES & GLA < RES & $18.5 \pm 0.19$ & $9.98 \pm 0.05^{*}$ & $1.82 \pm 0.02$ \\
GLA:OXYR & GLA < OXYR & GLA $>$ OXYR & $2.5 \pm 0.28$ & $2.05 \pm 0.07$ & $1.28 \pm 0.05$ \\
OXYR:RES & OXYR $>$ RES & OXYR $<$ RES & $12.5 \pm 0.05$ & $9.72 \pm 0.05^{*}$ & $1.36 \pm 0.04$ \\
PR:OXYR & PR $<$ OXYR & PR $<$ OXYR & $2.15 \pm 0.03$ & $1.82 \pm 0.10$ & $1.18 \pm 0.03$ \\
PR:RES & PR $>$ RES & PR $<$ RES & $17.5 \pm 0.28$ & $12.75 \pm 0.02 *$ & $1.35 \pm 0.05$ \\
\hline \multicolumn{7}{c}{ A significant difference $\left.{ }^{*} p<0.05\right)}$.
\end{tabular}

Table 4. $\mathrm{IC}_{50}$ values and $\mathrm{CI}$ values of mixtures with L-DOPA as a substrate.

\begin{tabular}{cccccc}
\hline Compounds & $\begin{array}{c}\text { Antioxidant } \\
\text { Activity }\end{array}$ & $\begin{array}{c}\text { Tyrosinase } \\
\text { Inhibitory Activity }\end{array}$ & $\begin{array}{c}\text { IC }_{\mathbf{5 0 m i x}} \\
(\boldsymbol{\mu m o l} / \mathbf{L})\end{array}$ & $\begin{array}{c}\text { IC }_{50 a d d} \\
(\boldsymbol{\mu m o l} / \mathbf{L})\end{array}$ & CI \\
\hline PR:GLA & PR $>$ GLA & PR $<$ GLA & $18 \pm 0.16$ & $23 \pm 0.01^{*}$ & $0.71 \pm 0.04$ \\
GLA:RES & GLA < RES & GLA < RES & $3.5 \pm 0.09$ & $3.3 \pm 0.17$ & $0.96 \pm 0.08$ \\
GLA:OXYR & GLA < OXYR & GLA $>$ OXYR & $8.1 \pm 0.03$ & $15.5 \pm 0.05^{*}$ & $0.57 \pm 0.01$ \\
OXYR:RES & OXYR $>$ RES & OXYR < RES & $2.9 \pm 0.16$ & $3.9 \pm 0.01^{*}$ & $0.75 \pm 0.05$ \\
PR:OXYR & PR $<$ OXYR & PR $<$ OXYR & $24 \pm 0.03$ & $25 \pm 0.02$ & $0.94 \pm 0.06$ \\
PR:RES & PR $>$ RES & PR $<$ RES & $6 \pm 0.01$ & $37 \pm 0.02^{*}$ & $0.78 \pm 0.02$ \\
\hline
\end{tabular}

A significant difference $\left(^{*} p<0.05\right)$.

OXYR had the highest DPPH clearance rate $\left(\mathrm{IC}_{50}=76 \pm 0.07 \mu \mathrm{mol} / \mathrm{L}\right)$. A synergistic effect can be produced when a strong tyrosinase inhibitor are combined, and synergistic effect is positively correlated with the DPPH clearance rate of a strong tyrosinase inhibitor. The DPPH clearance rate of RES $\left(\mathrm{IC}_{50}=142 \pm 0.03 \mu \mathrm{mol} / \mathrm{L}\right)$ was far higher than that of GLA $\left(\mathrm{IC}_{50}=458 \pm 0.037 \mu \mathrm{mol} / \mathrm{L}\right)$, indicating greater synergy in GLA + OXYR than in OXYR + RES.

When PR and OXYR were combined, the DPPH clearance rate $\left(\mathrm{IC}_{50}=119 \pm 0.07 \mu \mathrm{mol} / \mathrm{L}\right)$ and tyrosinase inhibition rate $\left(\mathrm{IC}_{50}=35.5 \pm 0.06 \mu \mathrm{mol} / \mathrm{L}\right.$, using L-DOPA as the substrate) of PR were both less than those of OXYR. Thus, the combination only showed an additive effect.

The DPPH clearance rate of PR was the second highest, whereas the inhibition rate of tyrosinase in the L-DOPA substrate was the lowest, indicating that combining it with either RES or GLA results in a synergistic effect. The synergy of GLA $+\mathrm{PR}(\mathrm{CI}=0.71 \pm 0.04)$ was greater than that of PR + RES $(\mathrm{CI}=0.78 \pm 0.02)$. The $\mathrm{CI}$ difference between the two mixtures was small because their DPPH clearance rates were relatively close.

The DPPH clearance rate and tyrosinase inhibition rate of RES $\left(\mathrm{IC}_{50}=2.5 \pm 0.28 \mu \mathrm{mol} / \mathrm{L}\right)$ in the L-DOPA substrate were higher than those of GLA $\left(\mathrm{IC}_{50}=6.0 \pm 0.23 \mu \mathrm{mol} / \mathrm{L}\right)$, indicating the additive effect in the mixture containing RES and GLA.

\subsection{Molecular Docking Strategy}

The binding ligands 2Y9X-OTR, 4IQK-IQK in 2Y9X, and 4IQK were contracted and re-docked to their respective receptors for the calculation of the RMSD. When the docking was completed, the best poses were selected and separately aligned with crystal conformations for the calculation of the RMSD. The results were 1.9186 and $1.0058 \AA$, indicating that the method effectively reproduced 
the experimental conditions. The comparisons between the docked poses and crystal ones are shown in Figure 1.

Based on the above study, the four drawn compounds were docked into two receptors, and the results are shown in Table 5. The interactions between the four compounds and receptors are depicted in Figures 2 and 3, respectively. "CDOCKER_INTERACTION ENERGY," which represents the level of interaction between the compound and the receptor, was calculated during the docking process. A low value reflects good interaction. As illustrated in Tables 2 and 5, a consistent result was achieved between molecular docking and mushroom tyrosinase inhibitory assay, indicating the good reliability of our results. For the four compounds, the level of molecular docking showed a trend similar to that observed in their effects on tyrosinase, indicating that the two methods can verified by using their results. For PR, the results of molecular docking and antioxidant activity did not show a similar trend. This finding may be related to the algorithm of CDOCKER, which includes the flexibility of the compound and considers the receptor to be rigid. For the other three compounds, the molecular docking and antioxidant activity results exhibited a similar trend, further verifying the reliability of the results.
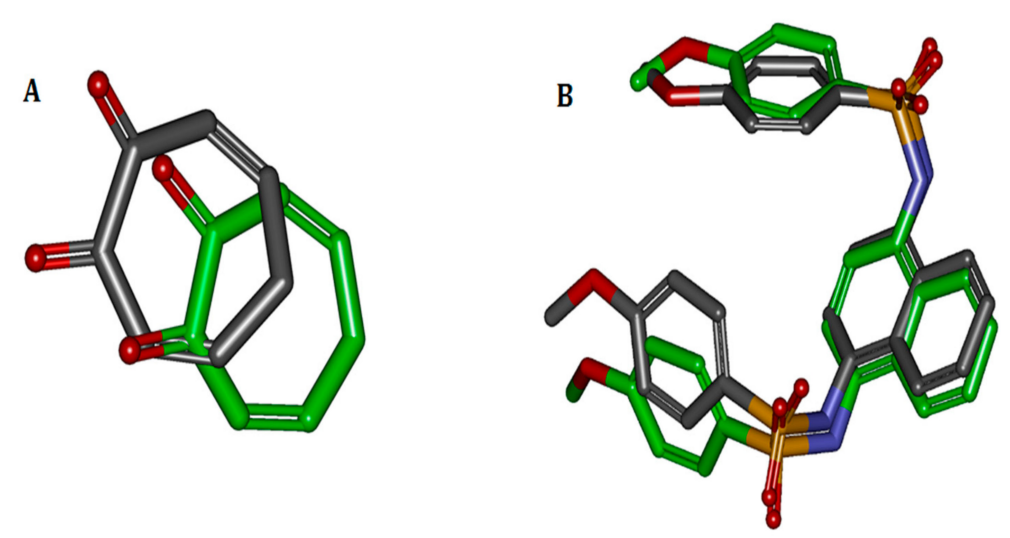

Figure 1. Comparisons between docked and crystal poses. Carbons in green are the crystal poses, whereas the others are docked. Comparison between (A) docked conformation and crystal conformation of 2Y9X-OTR with 1.9186 Å RMSD and (B) docked and crystal conformations of 4IQK-IQK with $1.0058 \AA$ RMSD.



Figure 2. Binding patterns of four compounds (carbons in yellow) in the binding site pocket of 2Y9X. The hydrogen bonds of docked conformation with important amino acids are shown in green dashed line. Interactions between (A) PR and 2Y9X; (B) OXYR and 2Y9X; (C) GLA and 2Y9X; and (D) RES and $2 Y 9 X$. 
A

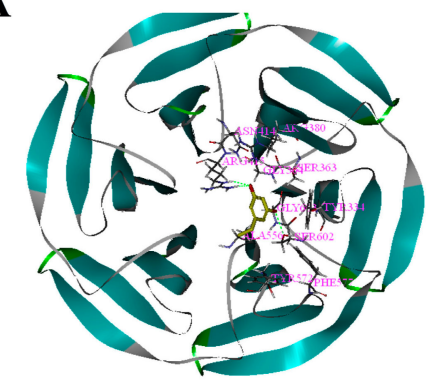

C

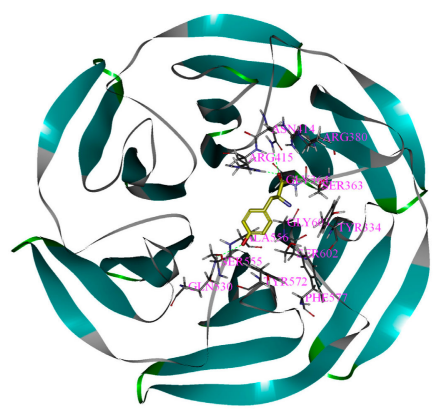

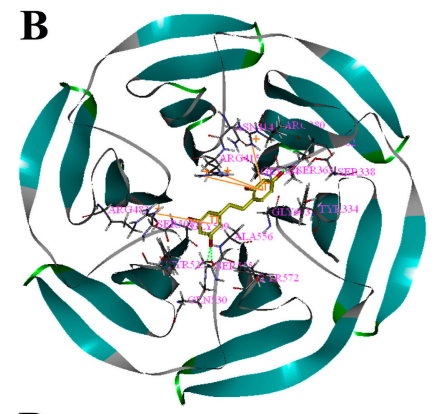

D

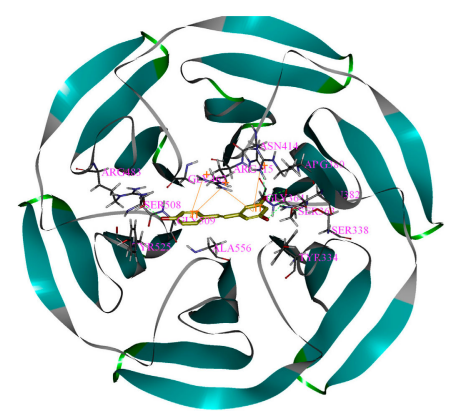

Figure 3. Binding patterns of four compounds (carbons in yellow) in the binding site pocket of 4IQK. The hydrogen bonds of docked conformation with important amino acids are shown in green dashed line. Interactions between (A) PR and 4IQK; (B) OXYR and 4IQK; (C) GLA and 4IQK; and(D) RES and $4 \mathrm{IQK}$.

Table 5. The results of four compounds docked to two receptors.

\begin{tabular}{ccccc}
\hline CDOCKER_INTERACTION ENERGY (Kcal/mol) & PR & OXYR & GLA & RES \\
\hline 2Y9X & -30.41 & -35.77 & -36.57 & -37.53 \\
4IQK & -20.22 & -33.37 & -26.35 & -30.94 \\
\hline
\end{tabular}

\subsection{Drug Synergism Analysis of RSE and OXYR in PIG1 Cell}

The MTT assays showed an inhibitory effect on PIG1 cells regardless of UVB dose. UVB doses at 100,200 , and $300 \mathrm{~mJ} / \mathrm{cm}^{2}$ caused significant effects on the PIG1 cells. However, $\geq 400 \mathrm{~mJ} / \mathrm{cm}^{2} \mathrm{UVB}$ resulted in high numbers of dead cells. The cell proliferative activity of the $300 \mathrm{~mJ} / \mathrm{cm}^{2}$ group was $95 \%$ of the control group but without statistical significance ( $p=0.1804$; Figure $4 \mathrm{~A}, \mathrm{~B})$. The tyrosinase inhibitory activities of isolated compounds on the L-DOPA substrate were examined.

Each compound was assayed at different concentrations. On the L-DOPA substrate, the mixture containing OXY and RES (9:1 ratio) showed a higher rate of inhibition against tyrosinase activities $\left(\mathrm{IC}_{50}=91.91 \mu \mathrm{M}\right)$ than either OXY $\left(\mathrm{IC}_{50}=113.8 \mu \mathrm{M}\right)$ or RES alone $\left(\mathrm{IC}_{50}>100 \mu \mathrm{M}\right)$. As shown in Figure $4 \mathrm{C}$, the mixture of OXY and RES inhibited tyrosinase activity in a dose-dependent manner. The inhibitory activity was significantly higher in the mixture compared to the sum of the inhibition rate of the samples containing OXY or RES alone $(p<0.01)$. When the concentration of OXY and RES was 90 and $10 \mu \mathrm{M}$, the mixture use was 1.68 times higher than that of the sum of the inhibition rate using OXY and RES alone. 


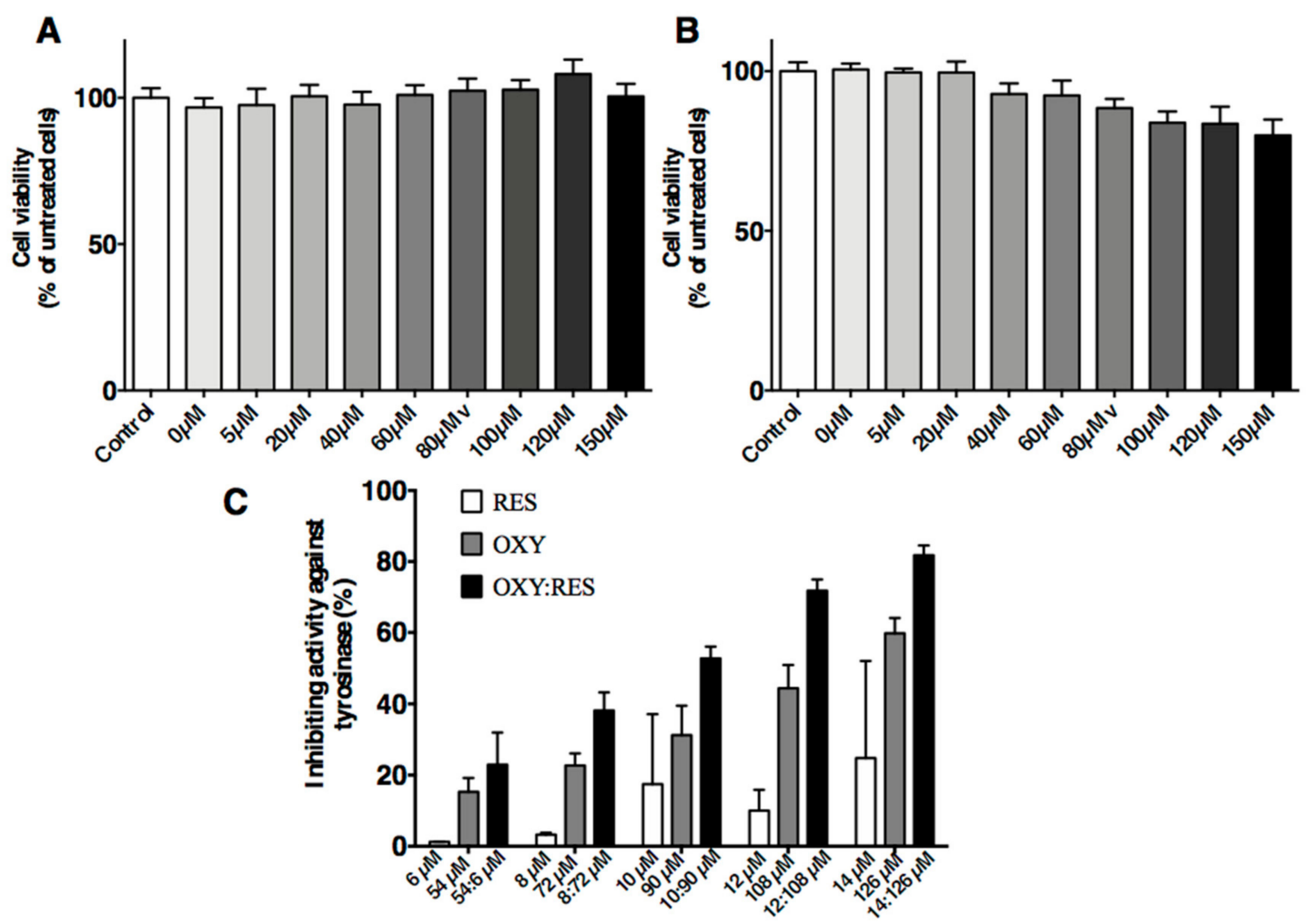

Figure 4. Effects of OXYR (A) and RES (B) on cell viability after UV irradiation. Dose-dependent inhibition of tyrosinase by OXY, RES and their mixture (C). The compounds were incubated with tyrosinase at $37^{\circ} \mathrm{C}$ with L-DOPA as substrate. The mixture consisted of OXY and RES (9:1 ratio). The \% inhibition was significantly higher in the mixture than the combined inhibition rates of the samples using OXY or RES alone $(p<0.01)$. Each bar shows the mean \pm SD of three independent tests.

\section{Discussion}

Pigmentation is a local color darkening shown on the skin surface, such as melasma and senile plaques. It is caused by UVA ray exposure, which leads to inflammatory reactions, changing the microenvironment of melanocytes in the skin. The above reactions promote melanin production [27-29].

Skin types vary according to the concentrations and qualities of eumelanin, which is a major pigment and photo protectant that protects the skin from damage [30]. Natural pigments and melanin in skin and hair seemingly produce endogenous hydrogen. The capacity of eumelanin relies on molecular hydrogen production, which may play a role in protecting skin. To fight against oxidative stress-related disorders, eumelanin pools dihydrogen. This effective pooling must be regarded as a novel element of skin defense system. Eumelanin is usually considered as an absorbent filter or physical barrier of the skin against the penetration of damaging agents [31]. Molecular hydrogen plays major roles in various skin diseases. For instance, it can remove toxic ROS. For dark-skinned population [32], the more melanin-driven hydrogen works, the lower the risk for ROS-mediated skin diseases. Eumelanin forms a skin defense system by producing and pooling molecular hydrogen, and this system acts on toxic agents for the elimination of detrimental effects.

Nrf2, an essential transcription factor for controlling oxidative stress [33], is expressed in human skin tissues, such as human keratinocytes [34,35], melanocyte [4], and human dermal fibroblasts [36]. Cytoprotective antioxidants can be increased by antioxidant compounds through the nuclear accumulation of Nrf2 [36,37]. Some necessary connections seemingly exist between these two protective mechanisms of skin tissues because they both participate in ROS removal.

Tyrosinase is a key factor that limits melanogenesis [9]. Tyrosinase inhibitors are widely used in the cosmetic field owing to their skin-whitening effects [38] and in the food industry because 
of their inhibitory activity against the enzymatic browning of food products [39]. Unfortunately, the use of tyrosinase inhibitors has potential risks to the human body. For instance, kojic acid, arbutin, and hydroquinone are widely applied as inhibitory agents in the field of cosmetics and known to exhibit strong therapeutic effect. However, they cause serious side effects. Kojic acid and hydroquinone cause genotoxicity and carcinogenesis [40-42]. Arbutin is a glycosylated hydroquinone extracted from wheat, pear skins, and blueberry leaves and is easily converted to harmful hydroquinone on the skin surface [42]. Therefore, safe and stable agents are urgently needed. Kojic acid can cause contact dermatitis [43], and rhododendrol can induce vitiligo [44]. Therefore, effort must be devoted for the development of safe and effective tyrosinase inhibitors.

Currently, scientists have been working on the study of natural compounds that offer a direct synergistic effect for tyrosinase inhibition. Research shows that copper ion scavengers and tyrosinase exhibit synergistic effects with tyrosinase inhibitors (non-copper ion scavengers). However, with respect to the CI value, a moderate synergistic effect only exists between the two copper ion scavengers [45]. Moreover, melanin production can be inhibited by noncompetitive and competitive tyrosinase inhibitions in synergy [46].

The sequences of antioxidative activities of GLA, OXYR, PR, and RES and their inhibitory activities against tyrosinase were determined. Our results indicated that tyrosinase activity was greatly inhibited through synergistic between strong antioxidants and strong tyrosinase inhibitors. This synergistic effect was observed only when L-DOPA was used as substrate.

The synergistic effect produced by two compounds was not related to the mode of tyrosinase inhibition, because GLA [1], OXYR [25] and PR were non-competitive inhibitors of the mushroom, whereas RES is a Kcat or suicide inhibitor.

Tyrosinase oxidizes phenols to ortho-quinones (monooxygenase activity) or catechols to ortho-quinones (oxidase activity) in catalytic reactions. It possesses four discrete oxidation states, namely, deoxy-, oxy-, met-, and deact-tyrosinase. The activity of tyrosinase is the first step in melanogenesis, indicating the oxidation of phenols to ortho-quinones by oxy-tyrosinase $[47,48]$. The activity mentioned above also shows the oxidation of bisphenol to quinone at the same time $[2,3,5,13,14,18,32,34,37,38,49]$. Thus, the activity of tyrosinase reflects the whole oxidation process of phenol to quinone through monooxygenase activity.

\section{Conclusions}

In this study, we demonstrated a novel synergistic compatibility effect among GLA, RES, OXYR, and PR. When the antioxidant activity of compound A was greater than that of compound $B$, and the inhibition of tyrosinase activity was weaker than compound B. Furthermore, the two compounds were combined in certain proportions. Compound A can increase the inhibition rate of B on tyrosinase, which can produce synergistic effect in vitro when L-DOPA is used as substrate. Finally, we selected RES + OXYR and used PIG1 cell to verify synergistic compatibility and obtained the same result.

Acknowledgments: This work is supported by grants from the National Natural Science Foundation of China (No. 81602773).

Author Contributions: Yan Wang designed the experimental scheme and wrote the the manuscript; Mi-Mi Hao, Li-Feng Wang, Hao Wang, Hong-Yan Li and Zhen Yang performed experiments; Peng-Wei Zhuang and Yan-Jun Zhang analyzed the data; Ying Sun revised the paper.

Conflicts of Interest: The authors declare no conflict of interest.

\section{References}

1. Birch-Machin, M.A.; Bowman, A. Oxidative stress and ageing. Br. J. Dermatol. 2016, 175, 26-29. [CrossRef] [PubMed]

2. Bae, J.Y.; Lim, S.S.; Kim, S.J.; Choi, J.S.; Park, J.; Ju, S.M.; Han, S.J.; Kang, I.J.; Kang, Y.H. Bog blueberry anthocyanins alleviate photoaging in ultraviolet-B irradiation-induced human dermal fibroblasts. Mol. Nutr. Food Res. 2009, 53, 726-738. [CrossRef] [PubMed] 
3. Giampieri, F.; Alvarez-Suarez, J.M.; Tulipani, S.; Gonzales-Paramas, A.M.; Santos-Buelga, C.; Bompadre, S.; Quiles, J.L.; Mezzetti, B.; Battino, M. Photoprotective potential of strawberry (Fragaria $\times$ ananassa) extract against UV-A irradiation damage on human fibroblasts. J. Agric. Food Chem. 2012, 60, 2322-2327. [CrossRef] [PubMed]

4. Chaiprasongsuk, A.; Onkoksoong, T.; Pluemsamran, T.; Limsaengurai, S.; Panich, U. Photoprotection by dietary phenolics against melanogenesis induced by UVA through Nrf2-dependent antioxidant responses. Redox Biol. 2016, 8, 79-90. [CrossRef] [PubMed]

5. Schafer, M.; Werner, S. Nrf2-A regulator of keratinocyte redox signaling. Free Radic. Biol. Med. 2015, 88, 243-252. [CrossRef] [PubMed]

6. Tarangini, K.; Mishra, S. Production, Characterization and Analysis of Melanin from Isolated Marine Pseudomonas sp. using Vegetable waste. Res. J. Eng. Sci. 2013, 2, 40-46.

7. Park, H.Y.; Kosmadaki, M.; Yaar, M.; Gilchrest, B.A. Cellular mechanisms regulating human melanogenesis. Cell. Mol. Life Sci. 2009, 66, 1493-1506. [CrossRef] [PubMed]

8. Wang, N.; Hebert, N. Tyrosinase maturation through the mammalian secretory pathway: Bringing color to life. Pigment Cell Res. 2006, 19, 3-18. [CrossRef] [PubMed]

9. Olivares, C.; Solano, F. New insights into the active site structure and catalytic mechanism of tyrosinase and its related proteins. Pigment Cell Melanoma Res. 2009, 22, 750-760. [CrossRef] [PubMed]

10. Jimbow, K.; Park, J.S.; Kato, F.; Hirosaki, K.; Toyofuku, K.; Hua, C.; Yamashita, T. Assembly, Target-Signaling and Intracellular Transport of Tyrosinase Gene Family Proteins in the Initial Stage of Melanosome Biogenesis. Pigment Cell Res. 2000, 13, 222-229. [CrossRef] [PubMed]

11. Simmler, C.; Pauli, G.F.; Chen, S.N. Phytochemistry and biological properties of glabridin. Fitoterapia 2013, 90, 160-184. [CrossRef] [PubMed]

12. Chen, J.; Yu, X.; Huang, Y. Inhibitory mechanisms of glabridin on tyrosinase. Spectrochim. Acta Part A Mol. Biomol. Spectrosc. 2016, 168, 111-117. [CrossRef] [PubMed]

13. Kolahdouz Mohammadi, R.; Arablou, T. Resveratrol and endometriosis: In vitro and animal studies and underlying mechanisms. Biomed. Pharmacother. 2017, 91, 220-228. [CrossRef] [PubMed]

14. Ortiz-Ruiz, C.V.; Ballesta de Los Santos, M.; Berna, J.; Fenoll, J.; Garcia-Ruiz, P.A.; Tudela, J.; Garcia-Canovas, F. Kinetic characterization of oxyresveratrol as a tyrosinase substrate. IUBMB Life 2015, 67, 828-836. [CrossRef] [PubMed]

15. Schmaus, G.; Vielhaber, G.; Jacobs, K.; Franke, H. 4-(1-Phenylethyl)1,3-benzenediol: A new highly potent lightening agent. J. Cosmet. Sci. 2006, 57, 197-198. [PubMed]

16. Bondet, V.; Brand-Williams, W.; Berset, C. Kinetics and Mechanisms of Antioxidant Activity using the DPPH Free Radical Method. LWT-Food Sci. Technol. 1997, 30, 609-615. [CrossRef]

17. Skroza, D.; Mekinić, I.G.; Svilović, S.; Šimat, V.; Katalinić, V. Investigation of the potential synergistic effect of resveratrol with other phenolic compounds: A case of binary phenolic mixtures. J. Food Compos. Anal. 2015, 38, 13-18. [CrossRef]

18. Mishra, G.P.; Sharma, R. Identification of Potential PPAR gamma Agonists as Hypoglycemic Agents: Molecular Docking Approach. Interdiscip. Sci. 2016, 8, 220-228. [CrossRef] [PubMed]

19. Zeng, Q.; Wang, Q.; Chen, X.; Xia, K.; Tang, J.; Zhou, X.; Cheng, Y.; Chen, Y.; Huang, L.; Xiang, H. Analysis of lncRNAs expression in UVB-induced stress responses of melanocytes. J. Dermatol. Sci. 2016, 81, 53-60. [CrossRef] [PubMed]

20. Verma, A.; Kushwaha, H.N.; Srivastava, A.K.; Srivastava, S.; Jamal, N.; Srivastava, K.; Ray, R.S. Piperine attenuates UV-R induced cell damage in human keratinocytes via NF-kB, Bax/Bcl-2 pathway: An application for photoprotection. J. Photochem. Photobiol. B Biol. 2017, 172, 139-148. [CrossRef] [PubMed]

21. Rong, J.; Shan, C.; Liu, S.; Zheng, H.; Liu, C.; Liu, M.; Jin, F.; Wang, L. Skin resistance to UVB-induced oxidative stress and hyperpigmentation by the topical use of Lactobacillus helveticus NS8-fermented milk supernatant. J. Appl. Microbiol. 2017, 123, 511-523. [CrossRef] [PubMed]

22. Chou, T.C. Theoretical basis, experimental design, and computerized simulation of synergism and antagonism in drug combination studies. Pharmacol. Rev. 1970, 326, 261-270. [CrossRef] [PubMed]

23. Kurin, E.; Mučaji, P.; Nagy, M. In vitro antioxidant activities of three red wine polyphenols and their mixtures: An interaction study. Molecules 2012, 17, 14336-16348. [CrossRef] [PubMed] 
24. Lorenz, P.; Roychowdhury, S.; Engelmann, M.; Wolf, G.; Wolf, G.; Horn, T.F.W. Oxyresveratrol and resveratrol are potent antioxidants and free radical scavengers: Effect on nitrosative and oxidative stress derived from microglial cells. Nitric Oxide 2003, 9, 64-76. [CrossRef] [PubMed]

25. Shin, N.H.; Shi, Y.R.; Choi, E.J.; Kang, S.H.; Chang, I.M.; Min, K.R.; Kim, Y. Oxyresveratrol as the Potent Inhibitor on Dopa Oxidase Activity of Mushroom Tyrosinase. Biochem. Biophys. Res. Commun. 1998, 243, 801-803. [CrossRef] [PubMed]

26. Satooka, H.; Kubo, I. Resveratrol as a kcat type inhibitor for tyrosinase: Potentiated melanogenesis inhibitor. Bioorg. Med. Chem. 2012, 20, 1090-1099. [CrossRef] [PubMed]

27. Randhawa, M.; Seo, I.; Liebel, F.; Southall, M.D.; Kollias, N.; Ruvolo, E. Visible Light Induces Melanogenesis in Human Skin through a Photoadaptive Response. PLoS ONE 2015, 10, e0130949. [CrossRef] [PubMed]

28. Che, D.N.; Xie, G.H.; Cho, B.O.; Shin, J.Y.; Kang, H.J.; Jang, S.I. Protective effects of grape stem extract against UVB-induced damage in C57BL mice skin. J. Photochem. Photobiol. B 2017, 173, 551-559. [CrossRef] [PubMed]

29. Puri, P.; Nandar, S.K.; Kathuria, S.; Ramesh, V. Effects of air pollution on the skin: A review. Indian J. Dermatol. Venereol. Leprol. 2017, 83, 415-423. [PubMed]

30. Natarajan, V.T.; Ganju, P.; Ramkumar, A.; Grover, R.; Gokhale, R.S. Multifaceted pathways protect human skin from UV radiation. Nat. Chem. Biol. 2014, 10, 542-551. [CrossRef] [PubMed]

31. Ostojic, S.M. Eumelanin-driven production of molecular hydrogen: A novel element of skin defense? Med. Hypotheses 2015, 85, 237-238. [CrossRef] [PubMed]

32. Brenner, M.; Hearing, V.J. The protective role of melanin against UV damage in human skin. Photochem. Photobiol. 2008, 84, 539-549. [CrossRef] [PubMed]

33. Dinkovakostova, A.T.; Kazantsev, A.G. Activation of Nrf2 signaling as a common treatment of neurodegenerative diseases. Neurodegener. Dis. Manag. 2017, 7, 97-100. [CrossRef] [PubMed]

34. Soeur, J.; Eilstein, J.; Lereaux, G.; Jones, C.; Marrot, L. Skin resistance to oxidative stress induced by resveratrol: From Nrf2 activation to GSH biosynthesis. Free Radic. Biol. Med. 2015, 78, 213-223. [CrossRef] [PubMed]

35. Kim, K.C.; Hyun, Y.J.; Hewage, S.; Piao, M.J.; Kang, K.A.; Kang, H.K.; Koh, Y.S.; Ahn, M.J.; Hyun, J.W. 3-Bromo-4,5-dihydroxybenzaldehyde Enhances the Level of Reduced Glutathione via the Nrf2-Mediated Pathway in Human Keratinocytes. Mar. Drugs 2017, 15, 291. [CrossRef] [PubMed]

36. Gao, W.; Lin, P.; Hwang, E.; Wang, Y.; Yan, Z.; Ngo, H.T.T.; Yi, T.H. Pterocarpus santalinus L. Regulated Ultraviolet B Irradiation-induced Procollagen Reduction and Matrix Metalloproteinases Expression through Activation of TGF- $\beta$ /Smad and Inhibition of the MAPK/AP-1 Pathway in Normal Human Dermal Fibroblasts. Photochem. Photobiol. 2017. [CrossRef] [PubMed]

37. Ben Yehuda Greenwald, M.; Frusic-Zlotkin, M.; Soroka, Y.; Ben Sasson, S.; Bitton, R.; Bianco-Peled, H.; Kohen, R. Curcumin Protects Skin against UVB-Induced Cytotoxicity via the Keap1-Nrf2 Pathway: The Use of a Microemulsion Delivery System. Oxid. Med. Cell. Longev. 2017, 2017, 5205471. [CrossRef] [PubMed]

38. Shimizu, K.; Kondo, R.; Sakai, K. Inhibition of tyrosinase by flavonoids, stilbenes and related 4-substituted resorcinols: Structure-activity investigations. Planta Medica 2000, 66, 11-15. [CrossRef] [PubMed]

39. Martinez, M.V.; Whitaker, J.R. The biochemistry and control of enzymatic browning. Trends Food Sci. Technol. 1995, 6, 195-200. [CrossRef]

40. Westerhof, W.; Kooyers, T.J. Hydroquinone and its analogues in dermatology-a potential health risk. J. Cosmet. Dermatol. 2005, 4, 55-59. [CrossRef] [PubMed]

41. Nohynek, G.J.; Kirkland, D.; Marzin, D.; Toutain, H.; Leclerc-Ribaud, C.; Jinnai, H. An assessment of the genotoxicity and human health risk of topical use of kojic acid[5-hydroxy-2-(hydroxymethyl)4H-pyran-4-one]. Food Chem. Toxicol. 2004, 42, 93-105. [CrossRef] [PubMed]

42. Takizawa, T.; Imai, T.; Onose, J.; Ueda, M.; Tamura, T.; Mitsumori, K.; Izumi, K.; Hirose, M. Enhancement of hepatocarcinogenesis by kojic acid in rat two-stage models after initiation with $\mathrm{N}$-bis(2-hydroxypropyl)nitrosamine or N-diethylnitrosamine. Toxicol. Sci. 2004, 81, 43-49. [CrossRef] [PubMed]

43. Nakagawa, M.; Kawai, K.; Kawai, K. Contact allergy to kojic acid in skin care products. Contact Dermat. 1995, 32, 9-13. [CrossRef]

44. Tokura, Y.; Fujiyama, T.; Ikeya, S.; Tatsuno, K.; Aoshima, M.; Kasuya, A.; Ito, T. Biochemical, cytological, and immunological mechanisms of rhododendrol-induced leukoderma. J. Dermatol. Sci. 2015, 77, 146-149. [CrossRef] [PubMed] 
45. Hseu, Y.C.; Cheng, K.C.; Lin, Y.C.; Chen, C.Y.; Chou, H.Y.; Ma, D.L.; Leung, C.H.; Wen, Z.H.; Wang, H.M. Synergistic Effects of Linderanolide B Combined with Arbutin, PTU or Kojic Acid on Tyrosinase Inhibition. Curr. Pharm. Biotechnol. 2015, 16, 1120-1126. [CrossRef] [PubMed]

46. Jin, Y.H.; Lee, S.J.; Chung, M.H.; Park, J.H.; Park, Y.I.; Cho, T.H.; Lee, S.K. Aloesin and arbutin inhibit tyrosinase activity in a synergistic manner via a different action mechanism. Arch. Pharm. Res. 1999, $22,232$. [CrossRef] [PubMed]

47. Ramsden, C.A.; Riley, P.A. Tyrosinase: The four oxidation states of the active site and their relevance to enzymatic activation, oxidation and inactivation. Bioorg. Med. Chem. 2014, 22, 2388-2395. [CrossRef] [PubMed]

48. Ramsden, C.A.; Riley, P.A. Mechanistic aspects of the tyrosinase oxidation of hydroquinone. Bioorg. Med. Chem. Lett. 2014, 24, 2463-2464. [CrossRef] [PubMed]

49. Cheng, Q.X.; Song, K.K. Tyrosinase Recent Prospects. J. Xiamen Univ. Natl. Sci. 2006, 5, 731-737.

Sample Availability: Samples of the compounds are not available from the authors. 